\title{
Lesions of the Perirhinal Cortex but Not of the Frontal, Medial Prefrontal, Visual, or Insular Cortex Block Fear-potentiated Startle Using a Visual Conditioned Stimulus
}

\author{
Jeffrey B. Rosen, ${ }^{a}$ Janice M. Hitchcock, ${ }^{b}$ Mindy J. D. Miserendino, William A. Falls, Serge Campeau, and \\ Michael Davis \\ Yale University School of Medicine and Ribicoff Research Facilities of the Connecticut Mental Health Center, New Haven, \\ Connecticut 06508
}

The present study is part of an ongoing series of experiments aimed at delineation of the neural pathways that mediate fear-potentiated startle, a model of conditioned fear in which the acoustic startle reflex is enhanced when elicited in the presence of a light previously paired with shock. A number of cortical areas that might be involved in relaying information about the visual conditioned stimulus (the light) in fear-potentiated startle were investigated. One hundred thirty-five rats were given 10 light-shock pairings on each of 2 consecutive days, and 1-2 d later electrolytic or aspiration lesions in various cortical areas were performed. One week later, the magnitude of fear-potentiated startle was measured. Complete removal of the visual cortex, medial prefrontal cortex, insular cortex, or posterior perirhinal cortex had no significant effect on the magnitude of fear-potentiated startle. Lesions of the frontal cortex attenuated fear-potentiated startle by approximately $50 \%$. However, lesions of the anterior perirhinal cortex completely eliminated fear-potentiated startle. The effective lesions included parts of the cortex both dorsal and ventral to the rhinal sulcus and extended from approximately 1.8 to $3.8 \mathrm{~mm}$ posterior to bregma. Lesions slightly more posterior (2.3-4.8 $\mathrm{mm}$ posterior to bregma) or lesions that included only the perirhinal cortex dorsal to the rhinal sulcus had no effect. The region of the perirhinal cortex in which lesions blocked fear-potentiated startle projects to the amygdala, and thus may be part of the pathway that relays the visual conditioned stimulus information to the amygdala, a structure that is also critical for fear-potentiated startle. In addition, the present findings are in agreement with numerous studies in primates suggesting that the perirhinal cortex may play a more general role in memory.

\footnotetext{
Received Feb. 18, 1992; revised June 29, 1992; accepted July 2, 1992.

This research was supported by NIMH Grants MH-25642 and MH-47840, NINCDS Grant NS-18033, Research Scientist Development Award MH-00004 a grant from the Air Force Office of Scientific Research, and the State of Connecticut. J.B.R. was supported by postdoctoral National Research Service Award MH-09550. Our sincere thanks are extended to Leslie Fields for word processing assistance.

Correspondence should be addressed to Dr. Michael Davis, Yale University School of Medicine, Connecticut Mental Health Center, 34 Park Street, New Haven, CT 06508.

aPresent address: Biological Psychiatry Branch, National Institute of Mental Health, Building 10, Room 3N212, 9000 Rockville Pike, Bethesda, MD 20892.

'Present address: Marion Merrell Dow Research Institute, 2110 East Galbraith Road, Cincinnati, OH 45215.

Copyright (C) 1992 Society for Neuroscience $0270-6474 / 92 / 124624-10 \$ 05.00 / 0$
}

Fear-potentiated startle in the rat has been used to investigate brain structures and pathways that are important for the expression of conditioncd fcar (cf. Davis ct al., 1987; Hitchcock and Davis, 1991; Rosen et al., 1991). In this model, increased startle amplitude in the presence of a light previously paired with footshock is used as an index of fear. Because the neural pathway that mediates the acoustic startle has been delineated (Davis et al., 1982; Cassella and Davis, 1986b), the brain structures and their anatomical connections that are involved in various aspects of fear can be studied in a behavior with a known anatomical substrate. With this approach, the central nucleus of the amygdala and its direct projection to the startle pathway have been shown to be necessary for the expression of fearpotentiated startle (Hitchcock and Davis, 1986; Hitchcock and Davis, 1991; Rosen et al., 1991).

Although it is clear that the amygdala is critical for the expression of fear-potentiated startle, the brain structures that may activate the amygdala during presentation of the fearful stimulus (the light) are not known. Several structures could potentially carry visual information to the amygdala in the rat. The perirhinal and insular cortices project directly to the amygdala (Krettek and Price, 1977; Veening, 1978; Ottersen, 1982; Saper, 1982; McDonald and Jackson, 1987), and a number of studies in primates suggest that the perirhinal cortex plays a role in memory (Squire and Zola-Morgan, 1991). The perirhinal and insular cortices receive afferents from the visual cortices (Deacon et al., 1983; Miller and Vogt, 1984), secondary somatosensory cortical areas, lateral precentral area, anterior cingulate cortex, parietal cortex, and medial prefrontal and infralimbic cortical areas, and have extensive reciprocal connections (Krettek and Price, 1977; Beckstead, 1979; Deacon et al., 1983; Turner and Zimmer, 1984). Many of these areas also receive visual information directly from primary and secondary visual cortices (Miller and Vogt, 1984). In addition, the perirhinal and insular cortices also receive input from subcortical areas such as the suprageniculate nucleus (Guldin and Markowitsch, 1983) and the nucleus reuniens (Ohtake and Yamada, 1989), which in turn receive visual information either directly via the ventral nucleus of the lateral geniculate nucleus (LGN; Herkenham, 1978) or indirectly via the zona incerta (Herkenham, 1978; Ricardo, 1981; Watanabe and Kawana, 1982), which itself receives input from the ventral nucleus of the LGN (Swanson et al., 1974; Ribak and Peters, 1975; Roger and Cadusseau, 1985).

Because the amygdala may be activated by a number of cortical areas, an investigation of the effects of various cortical 
lesions on the expression of fear-potentiated startle with a visual conditioned stimulus (CS) was carried out. Separate lesions of the visual cortex, frontal cortex, medial prefrontal cortex, insular cortex, and the anterior and posterior parts of the perirhinal cortex were performed following training, but prior to testing. In a previous study, we found that lesions of the visual cortex blocked fear-potentiated startle when testing occurred 1-2 d after the lesion (Tischler and Davis, 1983). However, at this short lesion-to-test interval, which was used to minimize recovery of function, baseline levels of startle were markedly depressed, probably because of the extensive nature of this surgery. Because these nonspecific effects may have interfered with the measurement of fear-potentiated startle, the present study used a longer lesion-to-test interval.

Preliminary results of some of these experiments have been reported in abstract form (Rosen et al., 1989).

\section{Materials and Methods}

Animals. A total of 135 experimentally naive male albino SpragueDawley rats (Charles River Co.) that weighed 300-350 gm at the time of surgery were used. They were housed in group cages of two or three rats each until surgery, after which they were housed individually. Rats were maintained on a $12 \mathrm{hr}$ light/12 hr dark schedule (lights on at 7 A.M.) with food and water available ad lib.

Potentiated startle training apparatus. Five identical boxes $(30 \times 25$ $\times 25 \mathrm{~cm}$ ) were used during training. The side and tops of the boxes were made of aluminum; the fronts and backs of clear Plexiglas. The floors consisted of $4.76 \mathrm{~mm}$ stainless steel bars spaced $19 \mathrm{~mm}$ apart. The boxes were located on two shelves within a $1 \times 1 \times 2 \mathrm{~m}$ ventilated, sound-attenuating chamber. The conditioned stimulus (CS) was produced by an $8 \mathrm{~W}$ fluorescent light bulb (100 $\mu \mathrm{sec}$ rise time) located on the outside of the back wall of each training cage. The shocks (unconditioned stimulus) were delivered from five BRS/LVE shock generators (SGS-004) located outside the chamber. Shock intensities were measured with an oscilloscope across a $1 \mathrm{k} \Omega$ resistor in series with a $100 \mathrm{k} \Omega$ resistor connected between adjacent floor bars in the training cages. Current was defined as the root mean square voltage across a $1 \mathrm{k} \Omega$ resistor where $I(\mathrm{~mA})-0.707 \times 0.5 \times$ peak-to-peak voltage.

Startle testing apparatus. The apparatus used to measure startle has been described previously (Cassella and Davis, 1986a). Briefly, five separate stabilimeters were used to record the amplitude of the startle response. Each stabilimeter consisted of an $8 \times 15 \times 15 \mathrm{~cm}$ Plexiglas and wire mesh cage suspended between compression springs within a steel frame. Cage movement resulted in displacement of an accelerometer, and the resultant voltage was proportional to the velocity of displacement. Startle amplitude was defined as the maximal accelerometer voltage that occurred during the first $200 \mathrm{msec}$ after the startle stimulus was delivered and was measured with a specially designed circuit (Weiss and Davis, 1976) interfaced to a Macintosh II computer. The stabilimeters were housed in a dark, ventilated, sound-attenuating chamber, each $10 \mathrm{~cm}$ from a high-frequency speaker (Radio Shack Supertweeter). The startle stimulus was a $50 \mathrm{msec}$ burst of white noise having a rise time of $5 \mathrm{msec}$. The stimulus could be varied in intensity. Background white noise, provided by a Grason Stadler $901 \mathrm{~B}$ white noise generator, was $55 \mathrm{~dB}$ (sound pressure level).

Matching procedure. Prior to training, groups of rats were placed in the startle test cages and 5 min later presented with 30 noise bursts at a $20 \mathrm{sec}$ interstimulus interval. Three different intensities were used $(95$, $105,115 \mathrm{~dB}$ ), with 10 noise bursts at each intensity. These were presented in an irregular, balanced sequence across the session. The mean startle amplitudes across the 30 noise bursts were used to divide the rats into several groups with similar mean startle amplitudes before experimental testing began.

Training procedure. One day after matching, the animals were placed in the training cages, and after 5 min, 10 pairings (trials) of the light CS and a $0.6 \mathrm{~mA}$ shock unconditioned stimulus were presented. The shock was presented during the last $500 \mathrm{msec}$ of the $3700 \mathrm{msec}$ light at an average intertrial interval of $4 \mathrm{~min}$ (range, 3-5 min). The 10 conditioning trials were presented on 2 successive days, for a total of 20 conditioning trials.

Surgery. These experiments were carried out over a period of almost
2 years, involving several different animal shipments. Because of this, separate control groups (unoperated or sham lesions) were included in each individual study, so that lesion effects on potentiated startle could not be attributed to differences in animal shipments. During the course of these studies, it became apparent that lesions of the anterior perirhinal cortex could have dramatic effects on potentiated startle, but only when the lesions were in a particular area. Hence, a disproportionate number of animals were included in this anterior perirhinal group.

Surgeries were performed $24-48 \mathrm{hr}$ after the second training day. All animals were anesthetized with $8 \%$ chloral hydrate in saline $(1 \mathrm{ml} / 200$ $\mathrm{gm})$ and placed skull flat in a stereotaxic instrument. Lesions of the visual $(n=10)$, frontal $(n=9)$, and prefrontal $(n=10)$ cortices were performed by visually guided aspiration. The skin was retracted, and cither a holc was drilled in the skull (prefrontal cortex) or holes were drilled and the bone was chipped away with rongeurs (visual and frontal cortices). A glass Pasteur pipette connected to a collection trap and vacuum was used to aspirate both white and gray matter. The atlas of Paxinos and Watson (1986) was used as a guide to determine the extent of the aspirated cortex. In all surgeries, Gelfoam (Upjohn) was placed on top of the exposed brain tissue and the overlying skin closed with wound clips.

Lesions of the anterior $(n=27)$ and posterior $(n=6)$ perirhinal cortices, and the insular cortex $(n=5)$ were performed by electrolysis. The skin was retracted and the muscles attached to either side of the skull were cut and retracted. Holes were drilled in the skull above the cortex and the bone chipped away. For the anterior and posterior perirhinal cortices, two lesions were performed along the rhinal fissure on each side of the brain. The anterior-posterior axis was referenced from bregma; the lateral coordinates, from the midline; and the ventral direction, from the skull surface measured at bregma. The coordinates for the anterior perirhinal cortex lesion were $2.8 \mathrm{~mm}$ posterior, $6.4 \mathrm{~mm}$ lateral, and either $7.7(n=6)$ or $8.0(n=21) \mathrm{mm}$ ventral, and $4.0 \mathrm{~mm}$ posterior, $6.4 \mathrm{~mm}$ lateral, and either $7.9(n=6)$ or $8.2(n=21) \mathrm{mm}$ ventral. The coordinates for the posterior perirhinal lesions were 6.6 $\mathrm{mm}$ posterior, $6.5 \mathrm{~mm}$ lateral, and $7.1 \mathrm{~mm}$ ventral and $7.8 \mathrm{~mm}$ posterior, $6.1 \mathrm{~mm}$ lateral, and $6.4 \mathrm{~mm}$ ventral. Insular cortex lesions were made with five lesions on each side of the brain along the rhinal fissure. The coordinates were (1) $4.3 \mathrm{~mm}$ anterior, $3.7 \mathrm{~mm}$ lateral, and $5.2 \mathrm{~mm}$ ventral; (2) $3.1 \mathrm{~mm}$ anterior, $4.1 \mathrm{~mm}$ lateral, and $6.0 \mathrm{~mm}$ ventral; (3) $1.9 \mathrm{~mm}$ anterior, $4.9 \mathrm{~mm}$ lateral, and $6.8 \mathrm{~mm}$ ventral; (4) $0.7 \mathrm{~mm}$ anterior, $5.3 \mathrm{~mm}$ lateral, and $7.2 \mathrm{~mm}$ ventral; and (5) $0.5 \mathrm{~mm}$ posterior, $6.1 \mathrm{~mm}$ lateral, and $7.5 \mathrm{~mm}$ ventral. All lesions were performed with the same parameters $(0.1 \mathrm{~mA}$ DC anodal current for $50 \mathrm{sec})$ using Kopf model NE-300 stainless steel electrodes $(0.25 \mathrm{~mm}$ in diameter $)$ insulated to within $0.5 \mathrm{~mm}$ of the tip.

Sham lesions of the anterior perirhinal cortex $(n=19)$ were performed by lowering electrodes into the brain $2 \mathrm{~mm}$ above the target areas used for the lesion groups. Unoperated matched control rats were run throughout the entire experiment with each lesion group. These consisted of 10 prefrontal, 6 insular, 5 posterior perirhinal, and 20 anterior perirhinal unoperated control rats. Also, eight unoperated controls were run together with the visual and frontal lesion groups.

Potentiated startle testing procedure. At 5-6 d after surgery, the animals were tested for potentiated startle. They were placed in the startle test cages and after 5 min presented with 10 pretest $95 \mathrm{~dB}$ noise bursts followed by test stimuli consisting of 60 noise bursts at a $30 \mathrm{sec}$ interstimulus interval. Three noise intensities were used $(90,95,105 \mathrm{~dB})$, and half of each of these were presented in darkness (noise-alone trials) and half were presented $3,200 \mathrm{msec}$ after the onset of the light (lightnoise trials). The 10 occurrences of each of the six trial types were presented in a balanced, irregular order across the test session.

Histology. After testing, the animals were killed by chloral hydrate overdose and perfused intracardially with $0.9 \%$ saline followed by $10 \%$ formalin. The brains were stored in $10 \%$ formalin for at least 1 week. The unsliced brains were first photographed and then embedded in celloidin. Coronal sections $(40 \mu \mathrm{m})$ were cut through the lesions of the prefrontal, insular, and anterior and posterior perirhinal cortices. Every fourth section was mounted and stained with cresyl violet. The extent and location of the lesions were examined microscopically for completeness. Sections from every rat given lesions of the perirhinal cortex were transcribed onto atlas sections from Paxinos and Watson (1986).

Data analysis. The mean startle amplitude scores from the three startle stimulus intensities for the noise-alone and light-noise trials were pooled into single mean scores for each animal for the noise-alone and lightnoise trials. Individual repeated-measures ANOVAs were performed 

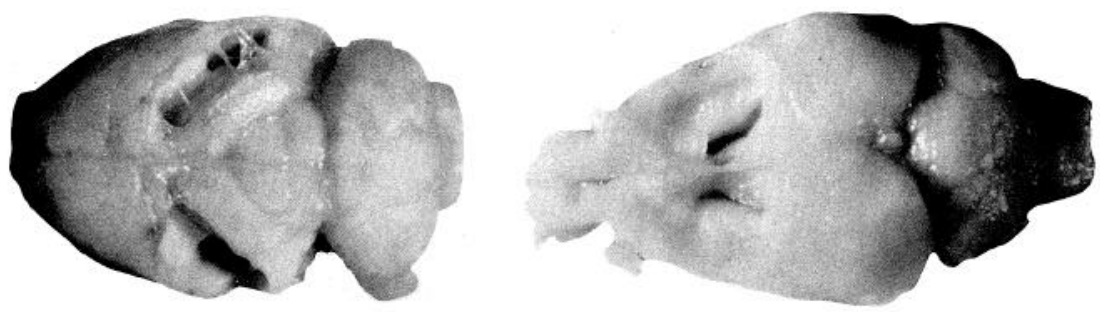

Figure 1. Top, Dorsal view of representative aspiration lesions of the visual cortex (left) and frontal cortex (right). Bottom, Mean amplitude startle response on noise-alone trials (solid bars), light-noise trials (open bars), and difference $( \pm$ SEM) between noise-alone and light-noise trials (hatched bars) in unoperated $(n=8)$, visual cortex $(n=$ $10)$, and frontal cortex $(n=9)$ groups. *, The frontal cortex lesion significantly attenuated fear-potentiated startle $(p<$ $0.05) .+$, Baseline startle (noise-alone) was significantly increased in the visual cortex group $(p<0.05)$.

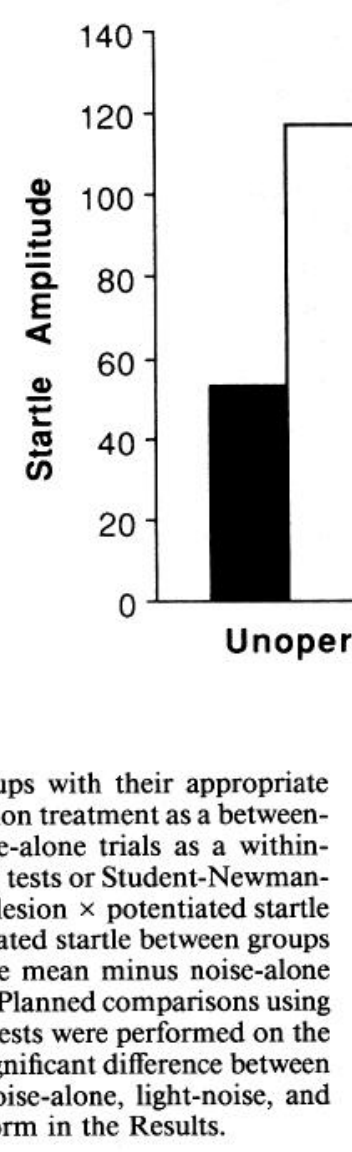

on these scores for the various lesion groups with their appropriate shams and/or unoperated controls, using lesion treatment as a betweensubjects factor and light-noise versus noise-alone trials as a withinsubjects factor. Planned comparisons using $t$ tests or Student-NewmanKeuls post hoc tests were performed on the lesion $\times$ potentiated startle data when a significant difference in potentiated startle between groups was indicated. Difference scores (light-noise mean minus noise-alone mean) were also calculated for each animal. Planned comparisons using $t$ tests or Student-Newman-Keuls post hoc tests were performed on the noise-alone data (baseline startle) when a significant difference between groups was indicated. Group means for noise-alone, light-noise, and difference scores are presented in graphic form in the Results.

\section{Results}

\section{Visual cortex and frontal cortex}

Aspiration lesions of the visual cortex included all occipital regions (Oc1B, Oc1M, Oc2L, Oc2ML, Oc2MM; designations from Zilles, 1985), retrosplenial cortex, and posterior parts of frontal, parietal (area 1), and hindlimb cortex. The lesions extended dorsally to include all cortical gray matter, the underlying white matter, and corpus callosum (Fig. 1, top). Aspiration lesions of the frontal cortex included areas 1,2 , and 3 of the frontal cortex, dorsal portions of the parietal cortex, the forelimb cortex, anterior sections of the hindlimb cortex, and the dorsal parts of the cingulate cortex. The lesions extended ventrally to include all cortical gray matter, the underlying white matter, and corpus callosum (Fig. 1, top).

The fear-potentiated startle scores for the visual cortex lesion, frontal cortex lesion, and the unoperated control group are shown in Figure 1 (bottom). The frontal cortex lesion group was analyzed with the visual cortex lesion group because both groups were tested together with the same unoperated control group. A repeated-measures ANOVA showed a significant overall difference between the light-noise and noise-alone trials $[F(1,24)$
$=70.4 ; p<0.0001]$, indicative of fear-potentiated startle. A significant treatment (lesion vs unoperated) $\times$ trial type (noisealone vs light-noise) interaction $[F(2,24)=3.8 ; p<0.05]$ was found. Post hoc analysis using the difference scores revealed that aspiration of the visual cortex did not significantly alter the magnitude of fear-potentiated startle, but the frontal cortex lesion attenuated fear-potentiated startle in comparison with the unoperated group $(p<.05)$. As shown in Figure 1 (bottom), the magnitude of this attenuation was about $50 \%$. In addition, baseline startle (noise-alone trials) was significantly higher in the visual cortex lesion group than in the unoperated group ( $p$ $<0.05$ ).

\section{Prefrontal cortex}

Aspiration lesions of the prefrontal cortex included the anterior part of the tenia tecta, dorsal peduncular cortex, infralimbic cortex, cingulate cortex anterior to the corpus callosum, and anteromedial portions (area 2) of the frontal cortex (Fig. 2, top). The fear-potentiated startle scores for the prefrontal cortex lesion and unoperated control groups are shown in Figure 2 (bottom). A repeated-measures ANOVA showed a significant overall difference between the light-noise and noise-alone trials $[F$ $(1,18)=19.3 ; p<0.0001]$, indicative of fear-potentiated startle. However, there was no treatment $\times$ trial type interaction $[F(1$, $18)=1.0, \mathrm{NS}]$ and no other significant differences between the two groups. These data indicate that lesions of the prefrontal cortex did not significantly alter the magnitude of fear-potentiated startle.

\section{Insular cortex}

The definition of the insular cortex from Paxinos and Watson (1986) was used to determine the caudal extent of the insular 

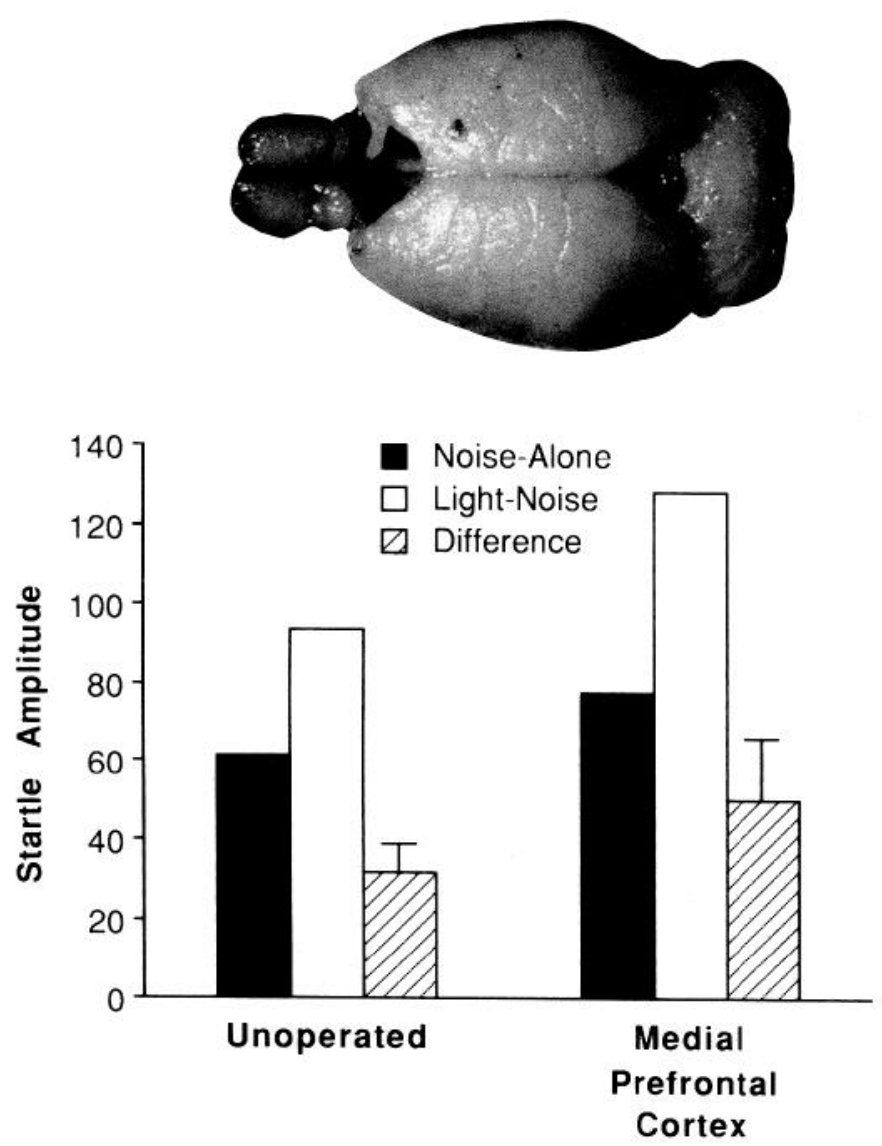

Figure 2. Top, Dorsal view of representative aspiration lesion of the medial prefrontal cortex. Bottom, Mean amplitude startle response on noise-alone trials (solid bars), light-noise trials (open bars), and difference $( \pm$ SEM) between noise-alone and light-noise trials (hatched bars) in unoperated $(n=10)$ and medial prefrontal cortex $(n=10)$ groups. The medial prefrontal cortex lesion had no significant effect on fear-potentiated startle.

cortex. From this definition, cortex adjacent to the claustrum was considered insular cortex. Electrolytic lesions of the insular cortex extended from approximately $3.5 \mathrm{~mm}$ anterior from bregma, where the forceps minor of the corpus callosum just becomes evident, to about $1.5 \mathrm{~mm}$ posterior to bregma, where the dorsal hippocampus begins to form from the fimbria (Fig. 3, top). Damage to the insular cortex was quite complete and included the claustrum. Some of the overlying parietal cortex was destroyed as well as a small area of the piriform cortex adjacent to the insular cortex. In one brain, the lateral edge of the caudate nucleus was also damaged. The fear-potentiated startle scores for the insular cortex lesion and unoperated control groups (Fig. 3 , bottom) showed a significant overall difference between the light-noise and noise-alone trials $[F(1,9)=31.5 ; p<0.0001]$, indicative of fear-potentiated startle. However, there was no treatment $\times$ trial type interaction $[F(1,9)=0.68, \mathrm{NS}]$ and no other significant differences between the two groups. These data indicate that lesions of the insular cortex did not significantly alter the magnitude of fear-potentiated startle.

\section{Perirhinal cortex}

The definition from Paxinos and Watson (1986) of the perirhinal cortex was used to determine the rostral and caudal extents of the perirhinal cortex. The cortex lies both above and below the
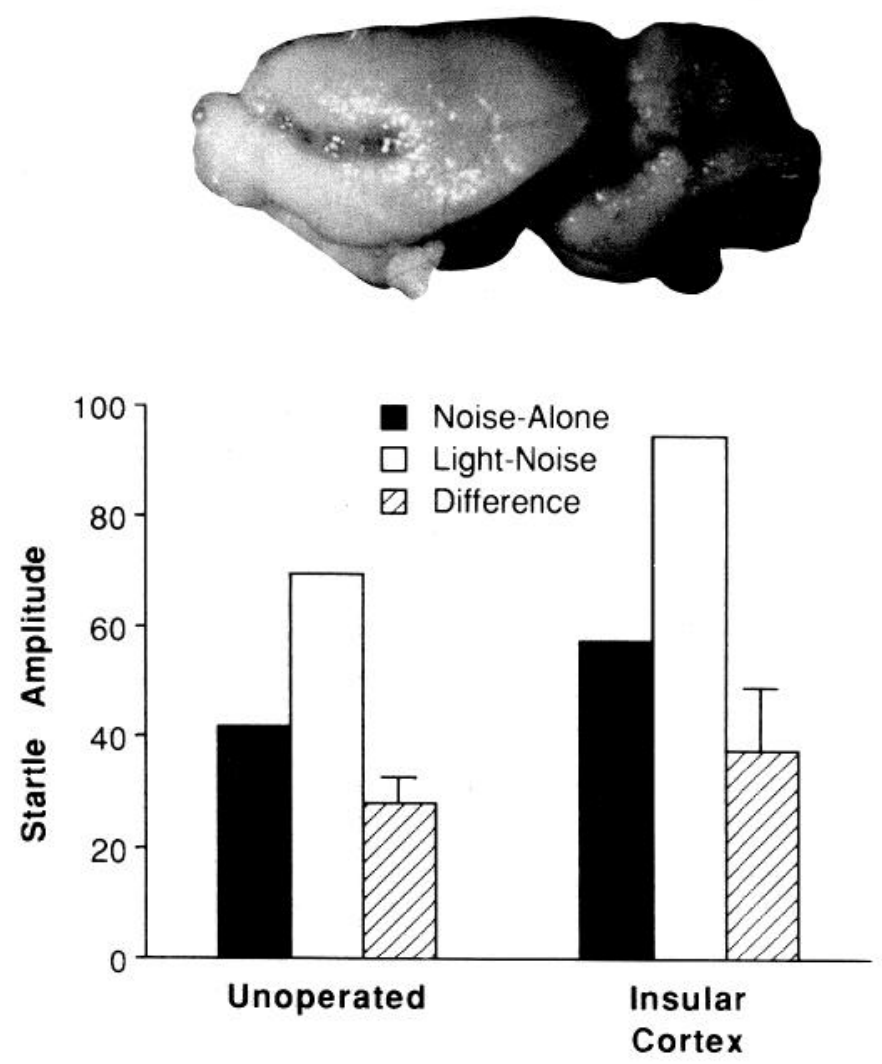

Figure 3. Top, Sagittal view of representative electrolytic lesion of the insular cortex. A similar lesion was made on the contralateral side in all animals with electrolytic lesions. Bottom. Mean amplitude startle response on noise-alone trials (solid bars), light-noise trials (open bars), and difference $( \pm$ SEM) between noise-alone and light-noise trials (hatched bars) in unoperated $(n=6)$ and insular cortex $(n=5)$ groups. The insular cortex lesion had no significant effect on fear-potentiated startle.

rhinal fissure rostrally from the most caudal extent of the insular cortex to the caudal pole of the cortex. Electrolytic lesions were made of either the posterior or anterior portions of the perirhinal cortex.

Posterior perirhinal cortex. Lesions of the posterior perirhinal cortex extended from about $6.0 \mathrm{~mm}$ posterior from bregma to the caudal pole of the cortex (Fig. 4, top). The subiculum, CA1, or $\mathrm{CA} 3$ regions of the hippocampus adjacent to the cortex, or the most caudal portion of the entorhinal cortex of several of the posterior-lesioned animals was also damaged. The fear-potentiated startle scores for the posterior perirhinal cortex lesion and unoperated control groups are shown in Figure 4 (bottom). A repeated-measures ANOVA showed a significant overall difference between the light-noise and noise-alone trials $[F(1,9)$ $=76.97 ; p<0.0001]$, indicative of fear-potentiated startle. However, there was no treatment $\times$ trial type interaction $[F(1$, $9)=2.64, \mathrm{NS}]$ and no other significant differences between the two groups. These data indicate that lesions of the posterior perirhinal cortex did not significantly alter the magnitude of fear-potentiated startle.

Anterior perirhinal cortex. In animals with lesions of the anterior perirhinal cortex, 13 showed essentially a complete blockade of fear-potentiated startle (less than $10 \%$ potentiation), while 14 showed potentiated startle similar to the unoperated control and sham rats. When all the brains were analyzed without knowledge of their startle scores, it was found that in the 13 

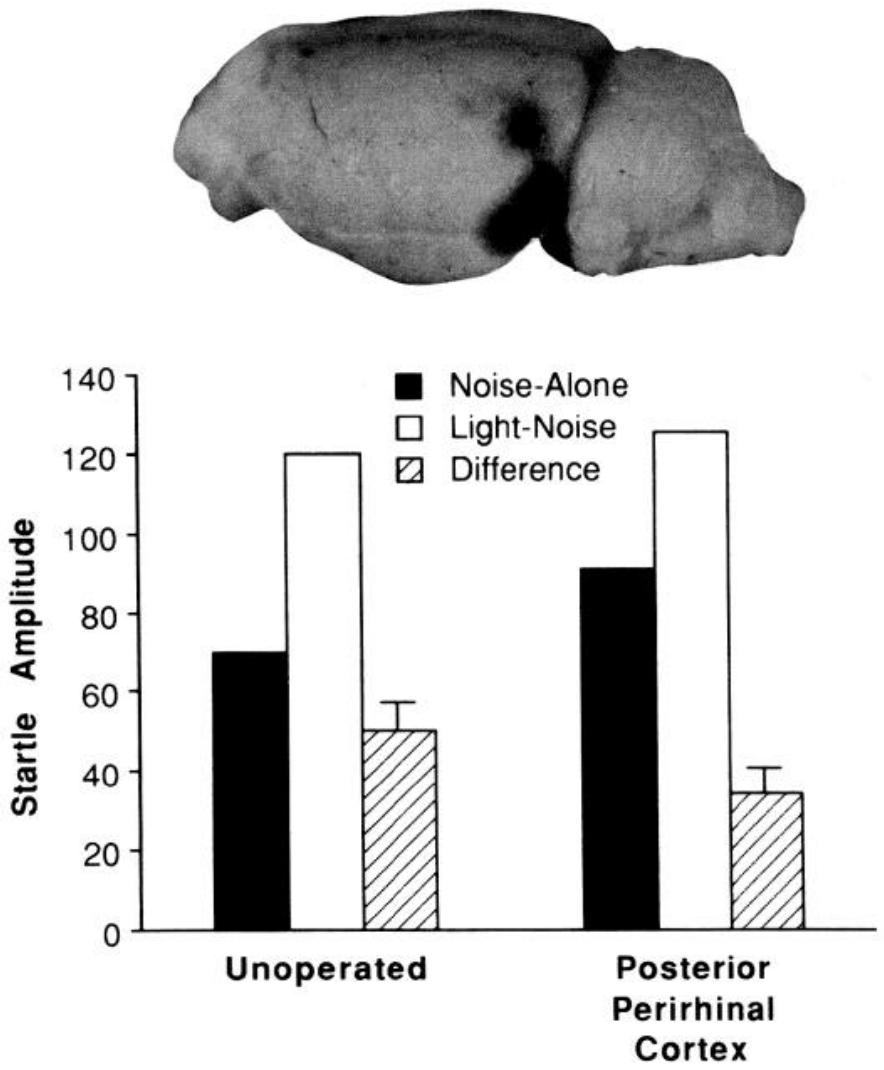

Figure 4. Top, Sagittal view of representative electrolytic lesion of the posterior perirhinal cortex. Bottom, Mean amplitude startle response on noise-alone trials (solid bars), light-noise trials (open bars), and difference $( \pm$ SEM) between noise-alone and light-noise trials (hatched bars) in unoperated $(n=5)$ and posterior perirhinal cortex $(n=6)$ groups. The posterior perirhinal cortex lesion had no significant effect on fearpotentiated startle.

animals in which potentiated startle was blocked, the anterior lesions typically began about $1.8 \mathrm{~mm}$ posterior from bregma and extended caudally to approximately $3.8 \mathrm{~mm}$ posterior from bregma (Fig. 5, top). In addition to perirhinal damage, the overlying parietal and temporal cortices also had varying amounts of damage. Slight damage was seen in the piriform and entorhinal cortices in portions lying adjacent to the perirhinal cortex. In these animals, damage was evident both above and below the rhinal sulcus. In six other animals in which there was no blockade of potentiated startle, the location of the lesions was essentially the same in terms of its rostrocaudal extent to the animals that showed a blockade, except there was little or no damage below the rhinal sulcus. Finally, in eight other animals in which potentiated startle was spared, there was damage both above and below the rhinal sulcus but the lesions typically began more caudally than the other groups, extending from approximately $2.3 \mathrm{~mm}$ posterior to bregma to approximately $4.8 \mathrm{~mm}$ posterior to bregma. Figure 6 shows reconstructions of a representative lesion that included the more rostral portion of the anterior perirhinal cortex (bregma -1.8 to -3.8 ), which blocked fear-potentiated startle, and a representative lesion that began more caudally in the anterior perirhinal cortex (bregma -2.3 to -4.8 ), which did not block fear-potentiated startle.

To analyze these data statistically, the anterior perirhinal lesion group was divided into the three groups described above and compared, along with sham-operated and unoperated con- trols (Fig. 5, bottom). A repeated-measures ANOVA found a significant overall difference between the light-noise and noisealone trials $[F(1,61)=95.03 ; p<0.0001]$, indicative of fearpotentiated startle. In addition, there was a significant treatment $\times$ trial type interaction $[F(4,61)=6.38 ; p<0.0001]$, indicating different levels of fear-potentiated startle in the different groups. Post hoc analysis of the difference scores revealed that the group with the perirhinal lesion extending from -1.8 to -3.8 posterior to bregma with damage above and below the rhinal sulcus was significantly different from all other groups $(p<0.01)$. As is evident in Figure 5 (bottom), the difference scores for the other groups were all very similar and did not differ statistically from each other. Finally, an overall ANOVA on the noise-alone trials (baseline startle) indicated a significant difference among the groups $[F(4,61)=3.53 ; p<0.01]$. Subsequent post hoc analysis revealed that the group with the lesion that blocked potentiated startle (bregma -1.8 to -3.8 ) had lower noise-alone startle amplitude than both the sham group and the group with the lesion that did not block potentiated startle (bregma -2.3 to $-4.8)(p<0.05)$. There were no other differences in baseline (noise-alone) startle.

Damage to the amygdala following lesions of the perirhinal cortex. Because the central, lateral, and basolateral amygdaloid nuclei are critically involved in fear-potentiated startle, special attention was given to whether lesions of the perirhinal cortex that blocked fear-potentiated startle involved concomitant damage of amygdaloid nuclei. No lesion ever damaged the central nucleus. In about half of the animals in which lesions of the perirhinal cortex blocked potentiated startle, some damage was seen in the lateral nucleus and also occasionally in the basolateral nucleus. However, this damage was usually only unilateral, which is not sufficient to block fear-potentiated startle (Sananes and Davis, 1992; C. B. Sananes and M. Davis, unpublished observations). Moreover, similar damage was observed in animals with slightly more posterior perirhinal lesions, which did not block potentiated startle. In the critical area from about 1.80 to $2.30 \mathrm{~mm}$ posterior to bregma, when lesions of the perirhinal cortex included damage above and below the rhinal sulcus, there was rarely damage to the lateral or basolateral amygdaloid nuclei and never bilateral damage. Figure 7 shows a photomicrograph of the animal reconstructed in Figure 6 indicating damage to the perirhinal cortex without damage to the lateral or basolateral amygdaloid nuclei. This animal had a complete blockade of fear-potentiated startle.

\section{Discussion}

The present study evaluated the effects of lesions of various cortical areas on the expression of fear-potentiated startle, using a visual conditioned stimulus. The data are summarized in Figure 8 . Fear-potentiated startle was not blocked by large lesions of various cortical areas that potentially could have been involved in fear-potentiated startle using light as a fear conditioned stimulus. Lesions of the insular, medial prefrontal, or posterior perirhinal cortex did not alter fear-potentiated or baseline startle. Lesions of the visual cortex increased baseline startle but did not significantly diminish fear-potentiated startle. Lesions of the frontal cortex attenuated fear-potentiated startle, but by only $50 \%$, possibly because of damage to the cingulate cortex, which has been shown to have a modulatory effect on fearconditioned bradycardia in rabbits (Buchanan and Powell, 1982). The only cortical area lesioned that blocked fear-potentiated startle completely was the anterior perirhinal cortex, and even 

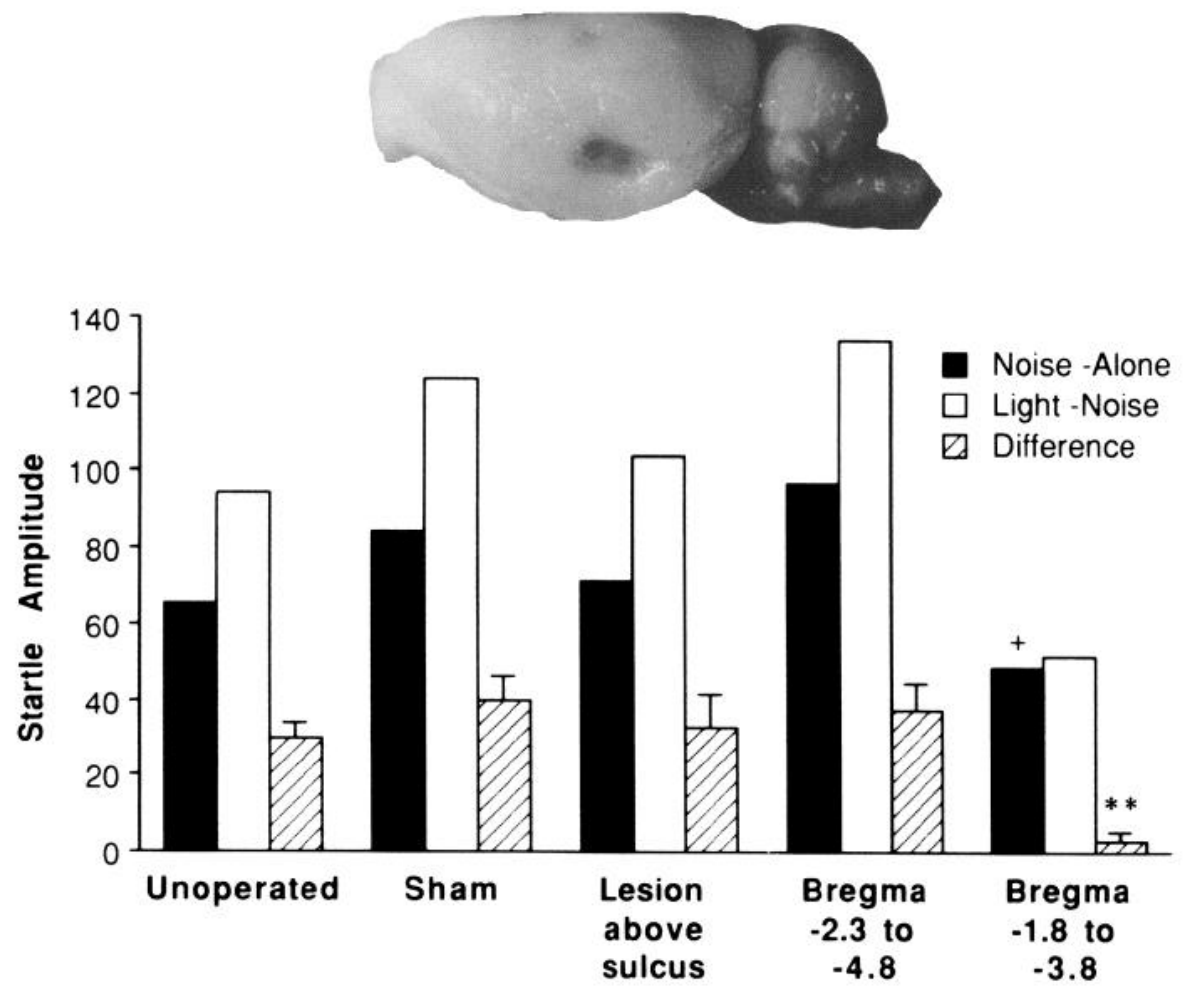

Figure 5. Top, Electrolytic lesion of the anterior perirhinal cortex that blocked fear-potentiated startle (breg$\mathrm{ma}-1.8$ to -3.8 ). Note damage both above and below the rhinal sulcus. Bot tom, Mean amplitude startle response on noise-alone trials (solid bars), lightnoise trials (open bars), and difference $( \pm$ SEM) between noise-alone and lightnoise trials (hatched bars) in the unoperated group $(n=20)$, sham group ( $n$ $=19)$, and the groups with anterior perirhinal lesions above the sulcus $(n=$ $6)$, at bregma -2.3 to $-4.8(n=8)$, and at bregma -1.8 to $-3.8(n=13)$. The anterior perirhinal cortex lesion at breg$\mathrm{ma}-1.8$ to -3.8 blocked fear-potentiated startle $\left({ }^{* *}, p<0.01\right)$ and decreased baseline (noise-alone) startle $(+$, $p<0.05$ ).

here, the lesion had to be quite specific. If it was slightly too posterior (about $1 \mathrm{~mm}$ ), or did not include damage both above and below the rhinal sulcus, it did not block potentiated startle. Because there were no animals with lesions only to parts of the anterior perirhinal cortex ventral to the rhinal sulcus, it is not yet clear whether such a lesion would be sufficient to block fearpotentiated startle.

Lesions of the anterior perirhinal cortex also significantly decreased baseline startle (noise-alone trials). Similarly, total blockade of potentiated startle in combination with a slight decrease in startle on noise-alone trials sometimes occurs with lesions of the amygdala (cf. Hitchcock and Davis, 1986). Recent data in our laboratory now indicate that the state of fear elicited by the visual conditioned stimulus may not fully decay within the $30 \mathrm{sec}$ intertrial interval employed in the present experiment. Thus, even startle on the noise-alone trials may be somewhat elevated by the state of fear elicited by the previously presented visual fear conditioned stimulus. If so, a lesion that completely blocked the ability of the visual stimulus to elicit fear might also be expected to decrease startle levels on the noise-alone trials. Further studies investigating the effects of perirhinal lesions on potentiated startle using longer interstimulus intervals during testing could be used to evaluate this possibility.

In comparison to the larger lesions of the visual, frontal, medial prefrontal, and insular cortices, the critical area of the perirhinal cortex was relatively small. Further, only the anterior part of the perirhinal cortex seemed to be crucial (an area judged to be about $1.8-3.8$ posterior to bregma based on Paxinos and Watson, 1986). Moreover, animals with perirhinal lesions that completely blocked fear-potentiated startle had little or no damage to anterior aspects of either the lateral or basolateral amygdaloid nuclei. There is some question as to whether this area is part of the perirhinal cortex or the insular cortex. We have used the demarcation of Paxinos and Watson (1986), in which the insular cortex is defined by its relationship to the claustrum, and the anterior perirhinal cortex begins as the claustrum ends. Others include this area of the anterior perirhinal cortex in the insular cortex (Krettek and Price, 1977; Deacon et al., 1983; Kosel et al., 1983; Zilles, 1985). In addition, to block fearpotentiated startle, the damage had to include the portion of the perirhinal cortex ventral to the rhinal fissure; lesions dorsal to the rhinal fissure did not affect fear-potentiated startle. This is interesting because afferents to the perirhinal area are quite segregated. Neocortical inputs from sensory cortices synapse dorsal to the rhinal fissure, while allocortical inputs and outputs (i.e., entorhinal, piriform) synapse ventral to the fissure (Deacon et al., 1983). Hence, afferent and/or efferent information from the limbic cortices to the anterior perirhinal cortex may be especially important for fear-potentiated startle.

As mentioned earlier, in contrast to the present results, previous studies in our laboratory found that lesions of the visual cortex blocked fear-potentiated startle when testing occurred 1$2 \mathrm{~d}$ after the lesion (Tischler and Davis, 1983). Because of the extensive nature of this surgery, it is possible that nonspecific postsurgical effects masked the measurement of fear-potentiated startle in that study. In fact, those lesioned animals had very low startle baselines, perhaps consistent with nonspecific depressant effects of the recent surgery. However, animals with equally severe surgical removal of anterior cortical areas also had very low startle baselines, yet showed high levels of potentiated startle (Tischler and Davis, 1983). An alternative explanation, therefore, is that $1-2 \mathrm{~d}$ after lesions of the visual cortex, disruption of normal neural transmission may have occurred in distant visual areas critical for potentiated startle, causing a blockade of potentiated startle. When, however, a longer lesionto-test interval (5-6 d) was employed in the present experiment, these effects may no longer have been operating, allowing potentiated startle to be expressed. In any case, it is clear from the 


\section{Blockade}

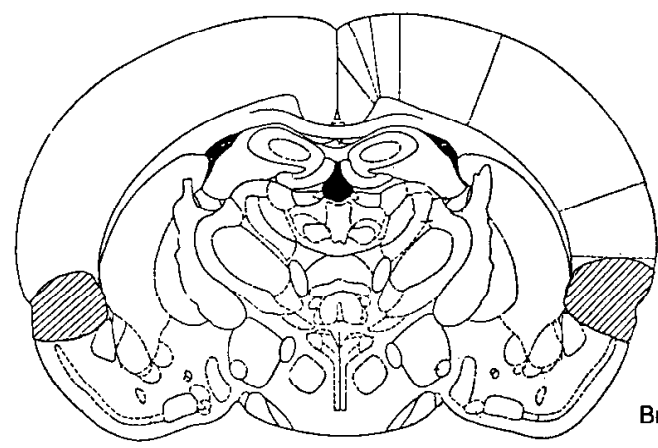

Bregma $-1.80 \mathrm{~mm}$

No Blockade
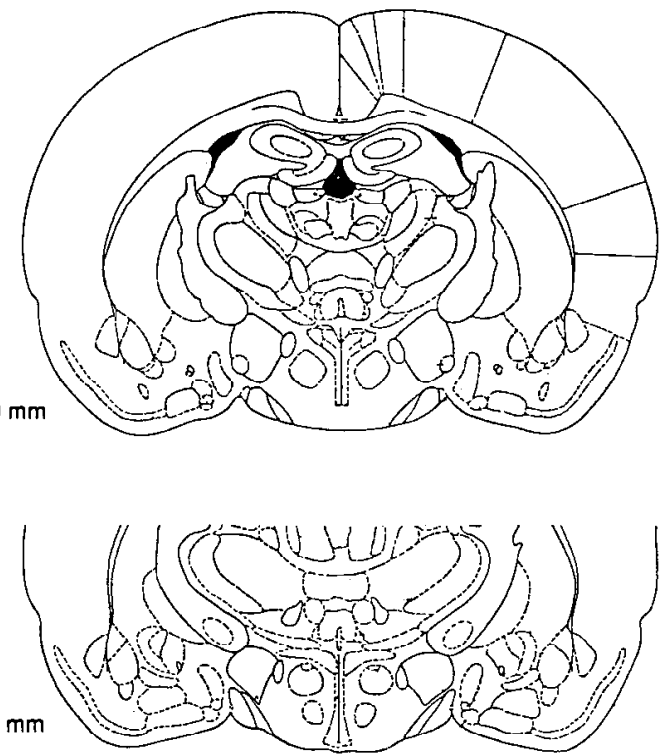

Bregma $-2.12 \mathrm{~mm}$

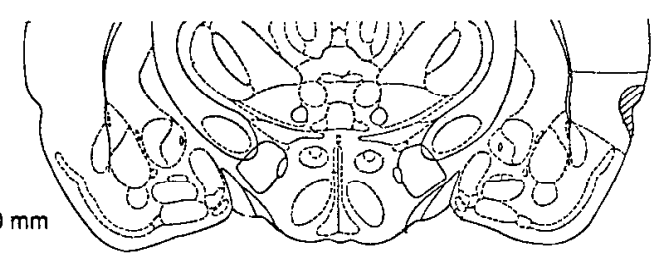

Bregma $-2.30 \mathrm{~mm}$
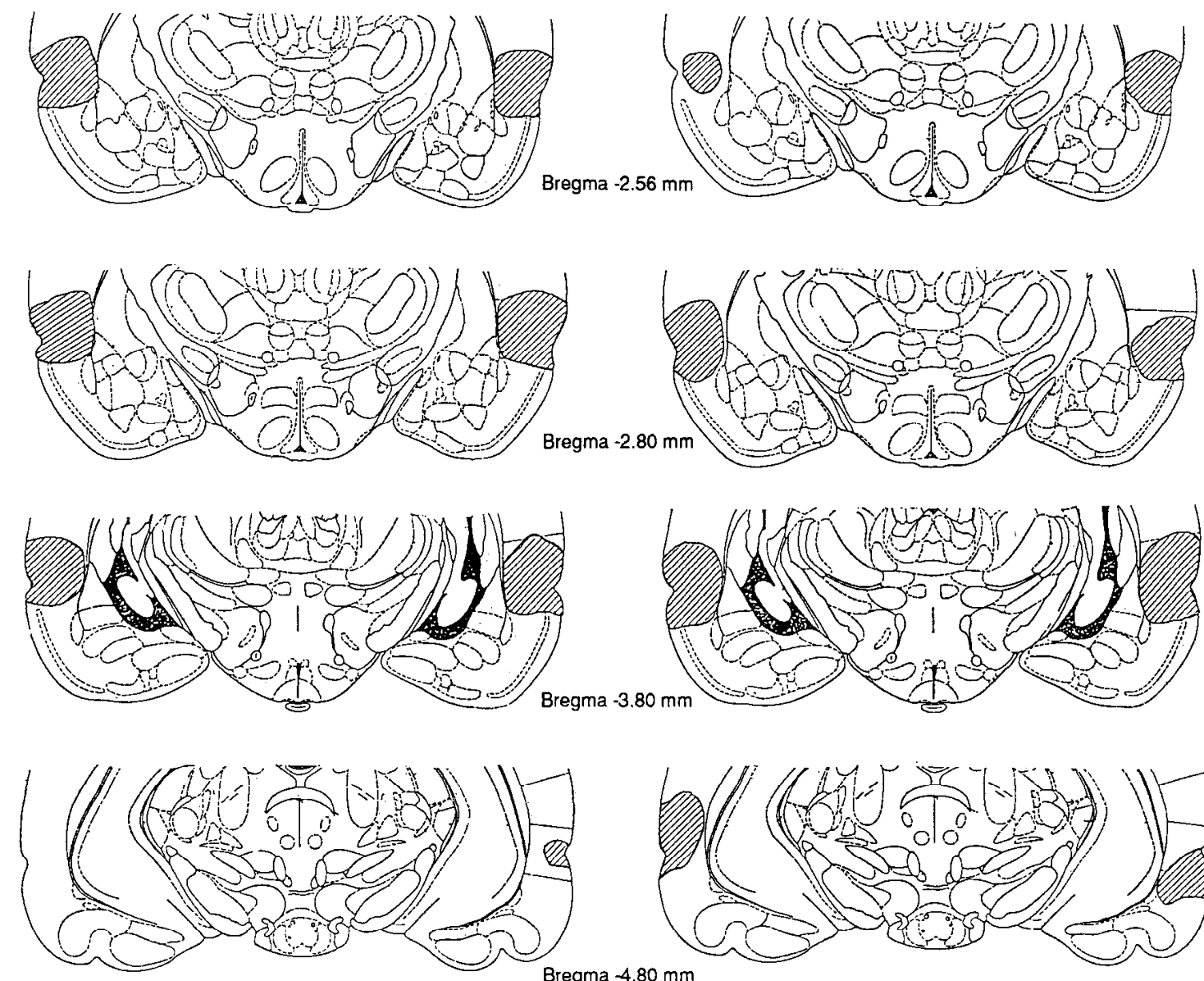

Bregma $-4.80 \mathrm{~mm}$

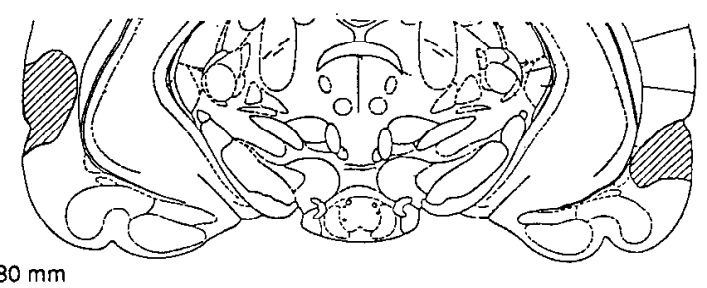




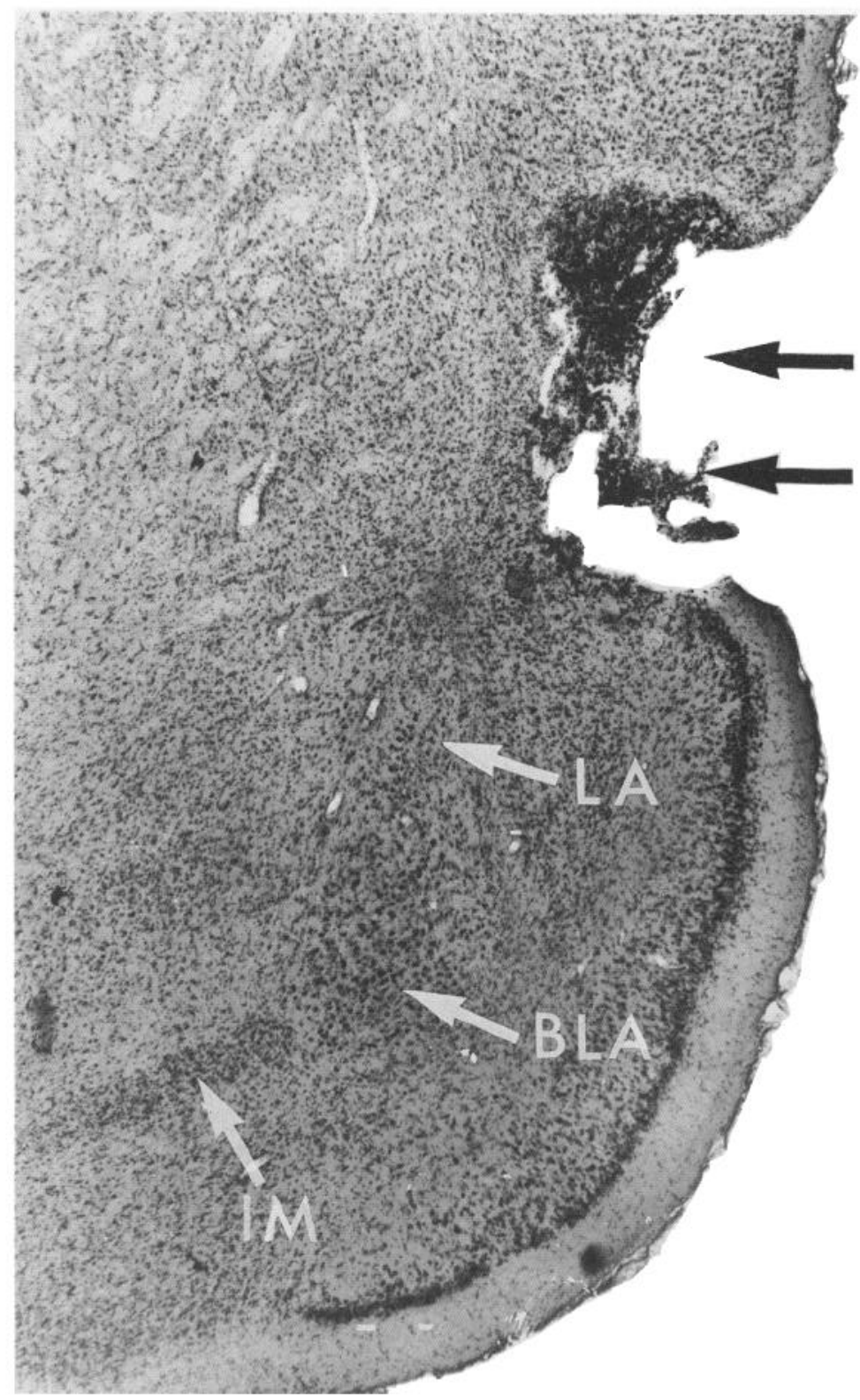

Figure 7. Photomicrograph of an animal with a complete blockade of fearpotentiated startle (entire lesion reconstructed in Fig. 6) showing damage to the perirhinal cortex (solid arrows) without damage to the lateral $(L A)$ or basolateral $(B L A)$ amygdaloid nuclei. $I M$, intercalated amygdaloid nucleus. present results, as well as several replications of this finding (W. A. Falls and M. Davis, unpublished observations), that the visual cortex is not required for the expression of fear-potentiated startle using a visual conditioned stimulus.

At this time, it is still not clear how visual information reaches the perirhinal cortex and/or the amygdala to mediate fear-potentiated startle using a visual stimulus. Previous work in our laboratory found that lesions of superficial layers of the superior colliculus, the pretectal area, parietal cortex, or the dorsal lateral lemniscus did not block potentiated startle (Tischler and Davis, 1983). It was also reported in that study that lesions of deep and intermediate layers of the superior colliculus blocked fearpotentiated startle when tested 1-2 d after the lesion. Recently, we have replicated this result with testing 6-7 d after lesions of deep and intermediate layers of the superior colliculus (J. M. Hitchcock and M. Davis, unpublished observations). However, baseline startle (noise-alone trials) was markedly elevated by the lesion. In fact, when these animals were retested using a very weak, $75 \mathrm{~dB}$ noise burst to elicit startle, they each showed increased startle in the presence of the light (fear-potentiated startle). Hence, we now believe that deep and intermediate layers of the superior colliculus, which project directly to the startle pathway at the level of the paralemniscal nucleus (Henkel and Edwards, 1978; Henkel, 1981), tonically inhibit acoustic startle. This effect may interfere with the measurement of fear-potentiated startle unless special test conditions are arranged. How-

Figure 6. Histological reconstructions of a representative anterior perirhinal cortex lesion that blocked fear-potentiated startle (left) and a representative anterior perirhinal cortex lesion that did not block fear-potentiated startle (right) at various levels posterior to bregma [drawn on sections from the atlas of Paxinos and Watson (1986); hatching delineates the lesioned area]. The lesion that blocked fear-potentiated startle (left) begins more rostrally. Reprinted with permission from Academic Press. 


\section{No Blockade}

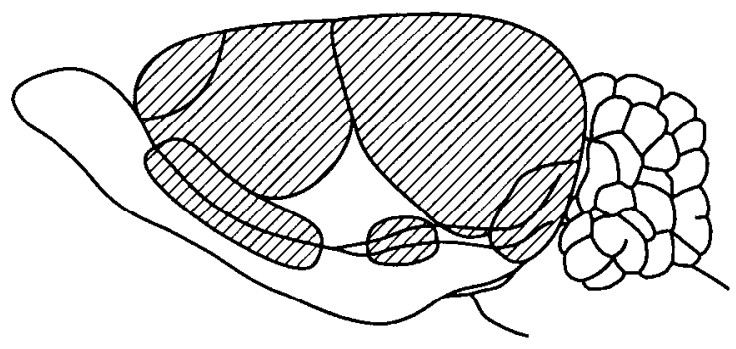

\section{Blockade}



Figure 8. Top, Sagittal view of cortical lesions (hatched areas) that did not completely block fear-potentiated startle using a visual conditioned stimulus. Bottom, Sagittal vicw of the antcrior pcrirhinal cortex lesion (shaded area) that blocked fear-potentiated startle using a visual conditioned stimulus.

ever, the deep and superficial layers of the superior colliculus may not be obligatory visual relays in fear-potentiated using a visual conditioned stimulus, although more extensive study of this problem will have to be carried out to be sure.

Tischler and Davis (1983) also found that electrolytic lesions that damaged parts of both the dorsal and ventral lateral geniculate nucleus blocked fear-potentiated startle. This has now been confirmed in several studies using both electrolytic and ibotenic acid lesions and with testing 5-7 d after the lesion (Falls and Davis, unpublished observations; Hitchcock and Davis, unpublished observations). Because the dorsal lateral geniculate nucleus projects only to the visual cortex, which is not critical for fear-potentiated startle, we are currently testing whether ibotenic acid lesions restricted to the ventral lateral geniculate nucleus will be sufficient to block fear-potentiated startle. If so, further studies will examine the role of connections between the ventral lateral geniculate nucleus and the perirhinal cortex (e.g., suprageniculate nucleus, zona incerta) in fear-potentiated startle.

It should be emphasized that all this work has been done by making lesions after conditioning has taken place. We believe this is the first way one should evaluate putative conditioned stimulus pathways in a behavioral test situation where conditions of training and testing can be separated easily. However, it is also critical to ask what these lesions might do to fearpotentiated startle when they are made before conditioning. In this case, certain structures might be crucially involved in the acquisition of visual learning, even though they might not be required for the expression of prior visual learning.

Although the present results strongly implicated the anterior perirhinal cortex in fear-potentiated startle, the exact role this structure plays in this learning paradigm is not known. The amygdala receives substantial input from the anterior perirhinal cortex, and the importance of the amygdala in the expression of fear-potentiated startle is well established. Lesions of the central or basolateral nucleus of the amygdala completely block the expression of fear-potentiated startle (Hitchcock and Davis, 1986, 1987; Sananes and Davis, 1992). Electrical stimulation of the central nucleus has been shown to enhance both acoustically and electrically elicited startle in untrained rats (Rosen and Davis, 1988a,b, 1990). Furthermore, a direct projection from the central nucleus of the amygdala to the startle circuit at the nucleus reticularis pontis caudalis has been demonstrated (Rosen et al., 1991), and lesions that interrupt this pathway at various levels block fear-potentiated startle (Hitchcock and Davis, 1991). It has therefore been suggested that activation of neurons in the central nucleus of the amygdala, which project directly to the startle circuit, modulates acoustic startle (Davis et al., 1987). Because of the substantial input of the perirhinal cortex to the amygdala, the anterior perirhinal cortex seems well suited to play a role in activating the amygdala. However, the amygdala and perirhinal cortex have considerable reciprocal connections (MacDonald and Jackson, 1987). Therefore, while the perirhinal cortex may play a role in a serial pathway relaying visual information to the amygdala, it may also play a more general role in visual and memorial processing. Indeed, recent results in primates (Murray and Mishkin, 1986; Zola-Morgan et al., 1989; Squire and Zola-Morgan, 1991) have shown that lesions of the perirhinal cortex and combined lesions of the perirhinal cortex and amygdala produce profound memory deficits.

Little is known about the function of the perirhinal cortex in the rat. In a study that specifically tested the effects of lesions of the perirhinal cortex, Meyer et al., (1986) showed that rats with lesions in this cortex could perform visual discriminations well, but had difficulty with stimulus-response relations using a visual cue. Similar findings have been reported in primates with temporal pole lesions (Mishkin, 1982). In an anatomical study, Horel and Stelzner (1981) argued that an area of rat cortex, very similar to the area of the anterior perirhinal cortex lesions of the present study, is analogous to the temporal pole in the primate (see Fig. 1 in Horel and Stelzner, 1981). Thus, lesions of the anterior perirhinal area in rat may provide a useful model to investigate the involvement of the temporal pole in learning and memory in the rodent as an adjunct to the studies examining the involvement of the temporal pole in learning and memory in the primate.

\section{References}

Beckstead RM (1979) An autoradiographic examination of corticocortical and subcortical projections of the medio-dorsal-projection (prefrontal) cortex of the rat. J Comp Neurol 184:43-62.

Buchanan SL, Powell DA (1982) Cingulate cortex damage attenuates conditioned bradycardia. Neurosci Lett 29:261-268.

Cassella JV, Davis M (1986a) The design and calibration of a startle measurement system. Physiol Behav 36:377-383.

Cassella JV, Davis M (1986b) Neural structures mediating acoustic and tactile startle reflexes and the acoustically-elicited pinna response in rats: electrolytic and ibotenic acid studies. Soc Neurosci Abstr 12: 1273.

Davis M, Gendelman DS, Tischler MD, Gendelman PM (1982) A primary acoustic startle circuit: lesion and stimulation studies. J Neurosci 2:791-805.

Davis M, Hitchcock JM, Rosen JB (1987) Anxiety and the amygdala: pharmacological and anatomical analysis of the fear-potentiated startle paradigm. In: The psychology of learning and motivation: advances in research and theory (Bower GH, ed), pp 263-305. San Diego: Academic. 
Deacon TW, Eichenbaum H, Rosenberg P, Eckman KW (1983) Afferent connections of the perirhinal cortex in the rat. J Comp Neurol 220:168-190.

Guldin WO, Markowitsch HJ (1983) Cortical and thalamic afferent connections of the insular and adjacent cortex of the rat. J Comp Neurol 215:135-153.

Henkel CK (1981) Afferent sources of a lateral midbrain tegmental zone associated with the pinnae in the cat as mapped by retrograde transport of horseradish peroxidase. J Comp Neurol 203:213-226.

Henkel CK, Edwards SB (1978) The superior colliculus control of pinna movements in the cat: possible anatomical connections. J Comp Neurol 182:763-776.

Herkenham M (1978) The connections of the nucleus reuniens thalami: evidence for a direct thalamo-hippocampal pathway in the rat. J Comp Neurol 177:589-610.

Hitchcock JM, Davis M (1986) Lesions of the amygdala, but not of the cerebellum or red nucleus, block conditioned fear as measured with the potentiated startle paradigm. Behav Neurosci 100:11-22.

Hitchcock JM, Davis M (1987) Fear-potentiated startle using an auditory conditioned stimulus: effect of lesions of the amygdala. Physiol Behav 39:403-408.

Hitchcock JM, Davis M (1991) Efferent pathway of the amygdala involved in conditioned fear as measured with the fear-potentiated startle paradigm. Behav Neurosci 105:826-842.

Horel JA, Stelzner DJ (1981) Neocortical projections of the rat anterior commissure. Brain Res 220:1-12.

Kosel KC, van Hoesen GW, Rosene DL (1983) A direct projection from the perirhinal cortex (area 35) to the subiculum in the rat. Brain Res 269:347-351.

Krettek JE, Price JL (1977) Projections from the amygdaloid complex and adjacent olfactory structures to the entorhinal cortex and to the subiculum in the rat and cat. J Comp Neurol 172:723-752.

McDonald AJ, Jackson TR (1987) Amygdaloid connections with posterior insular and temporal cortical areas in the rat. J Comp Neurol 262:59-77.

Meyer PM, Meyer DR, Cloud MD (1986) Temporal neocortical injuries in rats impair attending but not complex visual processing. Behav Neurosci 100:845-851.

Miller MW, Vogt BA (1984) Direct connections of rat visual cortex with sensory, motor, and association cortices. J Comp Neurol 226: 184-202.

Mishkin, M (1982) A memory system in the monkey. Philos Trans R Soc London [Biol] 298:85-95.

Murray EA, Mishkin M (1986) Visual recognition in monkeys following rhinal cortical ablations combined with either amygdalectomy or hippocampectomy. J Neurosci 6:1991-2003.

Ohtake T, Yamada H (1989) Efferent connections of the nucleus reuniens and the rhomboid nucleus in the rat: an anterograde PHA-L tracing study. Neurosci Res 6:556-568.

Ottersen OP (1982) Connections of the amygdala of the rat. IV. Corticoamygdaloid and intraamygdaloid connections as studied with axonal transport of horseradish peroxidase. J Comp Neurol 205:30-48.

Paxinos G, Watson C (1986) The rat brain in stereotaxic coordinates. New York: Academic.
Ribak CE, Peters A (1975) An autoradiographic study of the projections from the lateral geniculate body of the rat. Brain Res 92:341368.

Ricardo JA (1981) Efferent connections of the subthalamic region in the rat. II. The zona incerta. Brain Res 214:43-60.

Roger M, Cadusseau J (1985) Afferents to the zona incerta in the rat: a combined retrograde and anterograde study. J Comp Neurol 241: $480-492$.

Rosen JB, Davis M (1988a) Enhancement of acoustic startle by electrical stimulation of the amygdala. Behav Neurosci 102:195-202.

Rosen JB, Davis M (1988b) Temporal characteristics of the enhancement of startle by stimulation of the amygdala. Physiol Behav 44: 117-123.

Rosen JB, Davis M (1990) Enhancement of electrically elicited startle by amygdaloid stimulation. Physiol Behav 48:343-349.

Rosen JB, Hitchcock JM, Miserendino MJD, Davis M (1989) Lesions of the perirhinal cortex block fear-potentiated startle. Soc Neurosci Abstr 15:305.

Rosen JB, Hitchcock JM, Sananes CB, Miserendino MJD, Davis M (1991) A direct projection from the central nucleus of the amygdala to the acoustic startle pathway: anterograde and retrograde tracing studies. Behav Neurosci 105:817-825.

Sananes CB, Davis M (1992) $N$-methyl-D-aspartate lesions of the lateral and basolateral nuclei of the amygdala block fear-potentiated startle and shock sensitization of startle. Behav Neurosci 106:72-80.

Saper CB (1982) Convergence of the autonomic and limbic connections in the insular cortex of the rat. J Comp Neurol 210:163-173.

Squire LR, Zola-Morgan S (1991) The medial temporal lobe memory system. Science 253:1380-1386.

Swanson LW, Cowan WM, Jones EG (1974) An autoradiographic study of the efferent connections of the ventral lateral geniculate nucleus in the albino rat and the cat. J Comp Neurol 156:143-164.

Tischler MD, Davis M (1983) A visual pathway that mediates fearconditioned enhancement of acoustic startle. Brain Res 276:55-71.

Turner BH, Zimmer J (1984) The architecture and some of the interconnections of the rat's amygdala and lateral periallocortex. J Comp Neurol 227:540-557.

Veening JG (1978) Cortical afferents of the amygdaloid complex in the rat: an HRP study. Neurosci Lett 8:191-195.

Watanabe K, Kawana E (1982) The cells of origin of the incertofugal projections to the tectum, thalamus, tegmentum and spinal cord in the rat: a study using the autoradiographic and horseradish peroxidase methods. Neuroscience 7:2389-2406.

Weiss GT, Davis M (1976) Automated system for acquisition and reduction of startle response data. Pharmacol Biochem Behav 4:713 720.

Zilles K (1985) The cortex of the rat: a stereotaxic atlas. Berlin: Springer.

Zola-Morgan S, Squire LR, Amaral DG, Suzuki WA (1989) Lesions of the perirhinal and parahippocampal cortex that spare the amygdala and hippocampal formation producc scvere memory impairment. J Neurosci 9:4355-4370. 